\title{
Antihypertensive and Hypocholesterolemic Activity of a Novel Herbal Formulation of Fenugreek, Cumin and Ajowan in Rats
}

\author{
Surampalli Gurunath* \\ Department of Pharmacology, Bharat Institute of Technology (Pharmacy), Hyderabad, India
}

\begin{abstract}
Aims: To elucidate the antihypertensive and hypocholesterolemic effects of fenugreek, cumin, ajowan and their combined extracts along with enalapril maleate and fenofibrate in conscious $1 \mathrm{~K}-1 \mathrm{C}$ hypertensive and hypercholesterolemic rats respectively.

Materials and methods: Male Sprague-Dawley hypertensive rats were administered fenugreek, cumin, ajowan and their combined alcoholic extracts, which were compared with enalapril maleate (per oral). Blood pressure readings were taken on each of 3 days prior to drug treatment. Rats were divided into groups of six animals per dose, and each animal was used as its own control. Pre-drug and 2 hours post-drug blood pressure readings were recorded using the tail-cuff method. The antihypercholesterolemic study was carried out for 28 days. At the end of the treatment, the animals were fasted for 24 hours prior to the collection of blood samples. Blood was collected on the 8th, 15th and 29th days for measurement of plasma cholesterol, triglycerides and high density lipoprotein-cholesterol estimations using standard kits. The results were analyzed statistically using either paired $t$-test or ANOVA, followed by Dunnett's test; $p<0.05$ was considered to be significant.
\end{abstract}

Results: The seeds' of alcoholic extracts and their combination exhibited significant antihypertensive and antihypercholesterolemic effects at 300 and $500 \mathrm{mg}$ (per os) in conscious $1 \mathrm{~K}-1 \mathrm{C}$ hypertensive and hypercholesterolemic rats, at $p<0.05$ when compared to enalapril maleate and fenofibrate respectively.

Conclusions: The study reveals the antihypertensive and antihypercholesterolemic activity of fenugreek, cumin, ajowan and their combined extracts in hypertensive and hypercholesterolemic rats. The combined extract seems to be promising for the development of a phytomedicine for hypertension and atherosclerosis.

Introduction

Hypertension and atherosclerosis are the major causes of morbidity and mortality in industrialized societies, with hypertension being an atherosclerosis factor linked to cardiovascular risk. ${ }^{1,2}$ Myocar-

Keywords: Hypertension; Hypolipidemic; Fenugreek; Cumin; Ajowan; Atherosclerosis.

Abbreviations: HDL, high density lipoprotein; LDL, low density lipoprotein; VLDL, very low density lipoprotein.

Received: September 24, 2019; Revised: October 17, 2019; Accepted: November 18, 2019

"Correspondence to: Surampalli Gurunath, Department of Pharmacology, Bharat Institute of Technology (Pharmacy), Hyderabad, Telangana, India.

E-mail: s.gurunath1979@gmail.com

How to cite this article: Gurunath S. Antihypertensive and Hypocholesterolemic Activity of a Novel Herbal Formulation of Fenugreek, Cumin and Ajowan in Rats. $J$ Explor Res Pharmacol 2019;4(4):41-47. doi: 10.14218/JERP.2019.00011. dial infarction and cerebral ischemia are the major manifestations of circulatory diseases, such as hypertension and atherosclerotic vascular disease, which continue to be important public health risk factors in developed nation. ${ }^{3,4}$ The classic manifestations of hypertensive end-organ damage include vascular and hemorrhagic stroke, retinopathy, coronary heart disease/myocardial infarction and heart failure, proteinuria and renal failure, and in the vasculature, atherosclerotic changes, including the development of stenoses and aneurysms, ${ }^{5}$ result from prolonged rises in blood pressure. ${ }^{6}$

Hyperlipidemia (hypercholesterolemia) is a major cause of atherosclerosis- and atherosclerosis-associated conditions, such as coronary heart disease, ischemic cerebrovascular disease, and peripheral vascular disease. ${ }^{3-5}$ Animal and human studies have established the role of cholesterol in the development and progression of atherosclerosis. Low density lipoprotein (LDL)-cholesterol constitutes approximately $60-70 \%$ of total serum cholesterol. Epi- 
demiological studies directly implicated LDL-cholesterol in the development of atherosclerosis and coronary heart disease Atherosclerosis is three times more common in patients with hypertension, ${ }^{7,8}$ and there is a positive although not linear correlation between high blood pressure and atherosclerosis. ${ }^{9}$ Atherosclerosis is a complex multifactorial inflammatory disease, characterized by the presence of lesions due to the accumulation of lipids in the walls of large- and medium-sized arteries.

The clinical manifestation of atherosclerotic plaque formation is acute vascular occlusion due to the formation of a thrombus or clot, which can lead to ischemia of vital organs, such as heart causing myocardial infarction, brain resulting in stokes, and lower extremities causing peripheral artery disease. ${ }^{10,11}$ Clinically, many antihypertensive drugs are effective in reducing morbidity and mortality from athrosclerotically-mediated cardiovascular events. Since hypertension is a long-term disorder, the most perplexing problems in the management of hypertension are the adverse effects of antihypertensive drugs or their metabolites on the cardiovascular system. ${ }^{12}$ Today, use of herbal medicinal products and supplements has increased tremendously from the past three decades previous, with not less than $80 \%$ of people worldwide relying on them. ${ }^{13}$ Medicinal plants represent a great deal of untapped reservoir of drugs and the structural diversity of their component molecules makes a valuable source of novel lead compounds. ${ }^{14,15}$

Trigonella foenum-graecum L (Leguminoseae), commonly known as fenugreek, possess laxative, expectorant, hypocholesterolemic and hypoglycemic activities. ${ }^{16,17}$ Cumin (Cuminum cyminum), belonging to the family Umbelliferae, is a small slender annual herb about one foot in height, with grayish fruits, tapering towards both ends, and being compressed laterally. ${ }^{18}$ Fruits of cumin possess antimicrobial, mutagenic and estrogenic effects and also influence blood clotting. ${ }^{17}$ Ajowan (Trachyspermum ammi), belonging to the family Umbelliferae, is largely cultivated in Eastern India. The fruits are used as anthelmentic and hypotensive agents. ${ }^{18,19}$ The drug also intensifies coronary and myocardial circulation, acting as a mild positive ionotrope. Fenugreek seeds have been shown to possess antihypertensive and hypolipidemic activity. $^{20}$

Although the complementary and alternative medicine literature reported several studies with scientific evidence involving each herb towards the treatment of hypertension and atherosclerosis, no scientific study has been reported so far that evaluated the antihypertensive and hypolipidemic activity in their combinations as herbal formulations containing combined alcoholic extracts of fenugreek, cumin and ajowan. Therefore, the present study was designed to explore the effects of combined extracts of fenugreek, cumin and ajowan on blood pressure and the lipid profile in albino Wister and Sprague-Dawley rats.

\section{Materials and methods}

\section{Animals}

Albino rats of either sex (180-230 g) were used for the hypocholesterolemic study, whereas male Sprague-Dawley rats (250-300 g) were used for the antihypertensive study. Rats were procured from Venkatesh Enterprises, Bangalore, India. They were housed in groups of six in clean acrylic cages. The animals were maintained under natural day and night cycle. They were acclimatized for 1 week to the laboratory condition before starting the experiment. They were given the diet of standard pellet (Mahaveer Enterprises, Hyderabad, India) and allowed free access to food and water. All the animal studies were conducted in accordance with the guidelines for animal care. The study obtained prior approval from the Institutional Animal Ethical Committee, Hyderabad, with CPCSEA registration number 1015/PO/Re/S/06/CPCSEA, New Delhi (India).

\section{Preparation of extracts}

The Methi (fenugreek), Zeera (cumin) and Ajmud (ajowan) seeds were procured from the local market of Hyderabad, Telangana (India). The seeds were authenticated from the Botanical Survey of India, Pune (Maharastra) (Voucher specimen no. 557). About 150 $\mathrm{g}$ of powdered seeds of fenugreek, cumin, and ajowan were packed separately in the thimble of a soxhlet extractor and powders were subjected to extraction with $95 \%$ alcohol. The procedure was continued for about 20 cycles for each drug, one after another. The temperature was maintained around $60^{\circ} \mathrm{C}$ on an electric heating mantle with thermostat control. The extracts obtained were then distilled and the concentrated extracts were evaporated using a water bath to obtain a thicker mass.

\section{Drugs used}

Alcoholic extracts of fenugreek, cumin, ajowan and their combination in the proportion of 75:25:25 for fenugreek:cumin:ajowan respectively. Standard drugs like enalapril maleate (Evans, 10 mg; Cadila Health Care Ltd, Ahmedabad, India) and marketed preparation of fenofibrate $(200 \mathrm{mg} / \mathrm{kg}$ oral $)$ were used. The test drugs (300 mg/kg body weight) and combined extracts (300 and $500 \mathrm{mg} / \mathrm{kg}$ body weight) were administered orally as a suspension made using $1 \%$ gum acacia. The standard drug was administered as a suspension in distilled water at $3 \mathrm{mg} / \mathrm{kg}$ body weight (per $o s$ ). The oral drug administration was carried out making use of a pediatric oral feeding catheter and mouth gag, taking care to avoid intubation of the trachea. The doses of alcohol extracts were selected after performing acute toxicity studies according to the OECD Guidelines.

\section{Methods}

\section{Antihypertensive activity}

\section{Induction of experimental hypertension}

Animals were starved for $24 \mathrm{~h}$ prior to performing the surgical procedure, with free access to water. Sprague-Dawley rats weighing 250-300 g were anesthetized. The fur on the back was shaved and the skin disinfected. In the left lumbar area of the flank, an incision was made parallel to a long axis of the rat. The renal pedicel was exposed, with the kidney retracted to the abdomen. The renal artery was traced out and a U-shaped silver clip was clipped around it, near the aorta. Using a special forceps, the size of the clip was adjusted so that the internal gap ranged from $0.25-0.38$ $\mathrm{mm}$. The right kidney was removed after tying of the renal pedicle.

The skin incisions were closed and appropriate treatment was given to prevent infection to the wounds. Four to five weeks after clipping, blood pressure was measured and rats with values higher than $150 \mathrm{mmHg}$ were selected for the experiments. Blood pressure readings were taken on each of 3 days prior to drug treatment. Rats 
Table 1. Comparison of the effects of alcoholic extracts

\begin{tabular}{llll}
\hline Group & Before treatment & After treatment & Percentage inhibition \\
\hline Fenugreek, $300 \mathrm{mg} / \mathrm{kg}$ & $176.1 \pm 5.23$ & $160.5 \pm 4.64$ & 9.71 \\
Cumin, $300 \mathrm{mg} / \mathrm{kg}$ & $178.7 \pm 3.04$ & $161.7 \pm 7.03$ & 10.5 \\
Ajowan, $300 \mathrm{mg} / \mathrm{kg}$ & $160.9 \pm 3.81$ & $149.7 \pm 3.25$ & 7.48 \\
Combined extract, $300 \mathrm{mg} / \mathrm{kg}$ & $172.7 \pm 9.96$ & $139.4 \pm 7.16^{*}$ & 23.8 \\
Combined extract, $500 \mathrm{mg} / \mathrm{kg}$ & $169.8 \pm 7.74$ & $139.7 \pm 5.67^{*}$ & 21.5 \\
Enalapril maleate, $3 \mathrm{mg} / \mathrm{kg}$ & $162.2 \pm 5.26$ & $81.86 \pm 5.28^{* *}$ & 98.1 \\
\hline
\end{tabular}

Before and after treatment on blood pressure $(\mathrm{mmHg})$ in $1 \mathrm{~K}-1 \mathrm{C}$ Goldblatt hypertensive rats. Each value represents mean \pm standard error of the mean for groups of $n=6 .{ }^{*} p<$ $0.05, * * p<0.01$

were divided into groups of six animals per dose and each animal was used as its own control. Pre-drug and 2-h post-drug pressure readings were taken.

\section{Measurement of systolic blood pressure}

The systolic blood pressure was measured by the tail-cuff method using a Harvard noninvasive blood pressure apparatus. The acquisition of the data was made by the Biopack Data acquisition system and visualized on the computer screen. The tail-cuff was inflated and then deflated. Pulsations disappeared when the cuff was inflated. When the cuff started deflating, pulsation started appearing when pressure in the cuff equaled systolic pressure. The cuff was attached to the Harvard noninvasive blood pressure monitor and the blood pressure was recorded.

\section{Hypocholestrolemic activity}

Albino rats of either sex, weighing 200-250 g, were maintained under controlled conditions $\left[24 \pm 1{ }^{\circ} \mathrm{C} ; 30-70 \%\right.$; light-dark $(10 / 14 h)$ cycle] with free access to food and water.

\section{Collection of blood samples}

The animal was secured by tying in the supine position on a small operation table after anesthetizing with anesthetic ether. A 23-g hypodermic needle attached to a $2-\mathrm{mL}$ syringe was introduced into the heart, with the guidance of cardiac pulse. About $1 \mathrm{~mL}$ of blood was withdrawn at a time. Throughout the procedure, the animal was maintained under ether anesthesia. After the procedure, about $1.0 \mathrm{~mL}$ of normal saline was injected intraperitoneally into the animal. The animal was placed back in their respective cage after complete recovery from the anesthesia.

The study was carried for 28 days. Hyperlipidemia was induced in rats by administering cholesterol in coconut oil ( $15 \mathrm{mg} / \mathrm{kg}$, p.o.) for 7, 14 and 28 days. Concomitantly, the alcoholic extracts of fenugreek, cumin, and ajowan were administered at the dose of 300 $\mathrm{mg} / \mathrm{kg}$ per os, whereas their combined alcoholic extracts were administered at the two different doses of $300 \mathrm{mg} / \mathrm{kg}$ and $500 \mathrm{mg} / \mathrm{kg}$ per os respectively. The standard drug, fenofibrate, was administered at the dose of $200 \mathrm{mg} / \mathrm{kg}$ per os. The control animals received the appropriate amount of vehicle. At the end of the treatment, the animals were fasted for $24 \mathrm{~h}$ prior to the collection of blood samples. The blood was collected by cardiac puncture on the 8 th, 15 th and 29th days for measurement of plasma cholesterol, triglycerides and high density lipoprotein (HDL)-cholesterol estimations using standard kits.

Results

\section{Antihypertensive activity}

Effect on blood pressure in conscious $1 \mathrm{~K}-1 \mathrm{C}$ Goldblatt hypertensive rats

Half an hour after oral administration of the alcoholic extracts of fenugreek, cumin and ajowan and their combined extracts at the dose of $300 \mathrm{mg} / \mathrm{kg}$ or $500 \mathrm{mg} / \mathrm{kg}$ body weight, the systolic blood pressure was measured by the tail-cuff method. The blood pressure gradually decreased and reached a minimum level after 30 m of drugs' administration in the $1 \mathrm{~K} 1 \mathrm{C}$ Goldblatt hypertensive rats Table 1).

In extracts-treated groups of fenugreek, cumin, and ajowan, the systolic blood pressure reduced significantly $(p<0.05)$ from 176.1 $\pm 5.226 \mathrm{mmHg}$ to $160.5 \pm 4.635 \mathrm{mmHg}, 178.7 \pm 3.042 \mathrm{mmHg}$ to $161.7 \pm 7.032 \mathrm{mmHg}$ and $160.9 \pm 3.813 \mathrm{mmHg}$ to $149.7 \pm 3.248$ $\mathrm{mmHg}$ respectively. In groups treated with combined alcoholic extract of fenugreek, cumin and ajowan, the systolic blood pressure significantly $(p<0.05)$ reduced from $172.7 \pm 9.96 \mathrm{mmHg}$ to 139.4 $\pm 7.155 \mathrm{mmHg}$ and from $169.8 \pm 7.735 \mathrm{mmHg}$ to $139.7 \pm 5.67$ $\mathrm{mmHg}$ at $300 \mathrm{mg} / \mathrm{kg}$ and $500 \mathrm{mg} / \mathrm{kg}$ respectively, in the same ratio. In the same way, enalapril maleate was given at the dose of $3 \mathrm{mg} /$ $\mathrm{kg}$ orally and after $1 \mathrm{~h}$ of treatment, a drastic reduction in blood pressure was observed, with the mean systolic blood pressure reduced from $162.2 \pm 5.26 \mathrm{mmHg}$ to $81.86 \pm 5.28 \mathrm{mmHg}$; as well, the hypotensive effect was long lasting, with $p<0.01$ (Fig. 1). The combined alcoholic extracts of fenugreek, cumin and ajowan elicited a significant decrease in systolic blood pressure in a dosedependent manner compared to the individual alcoholic extracts. However, the mean systolic blood pressure reduction in enalapril treated group was more than the combined extract-treated group.

\section{Hypocholesterolemic activity}

Total cholesterol estimations ( $\mathrm{mg} \%)$

The mean values $83.52 \pm 2.26,107.4 \pm 3.372,103.2 \pm 5.612,98.4$ \pm 4.472 , and $91.6 \pm 2.493$ of fenofibrate, fenugreek, cumin, and combined extract at a dose of $300 \mathrm{mg} / \mathrm{kg}$ - or $500 \mathrm{mg} / \mathrm{kg}$-treated groups respectively showed significant $(p<0.01)$ decrease in total cholesterol compared to the control with mean value of $157.9 \pm$ 4.634. Similarly, the mean value $140.1 \pm 4.794$ of ajowan showed 


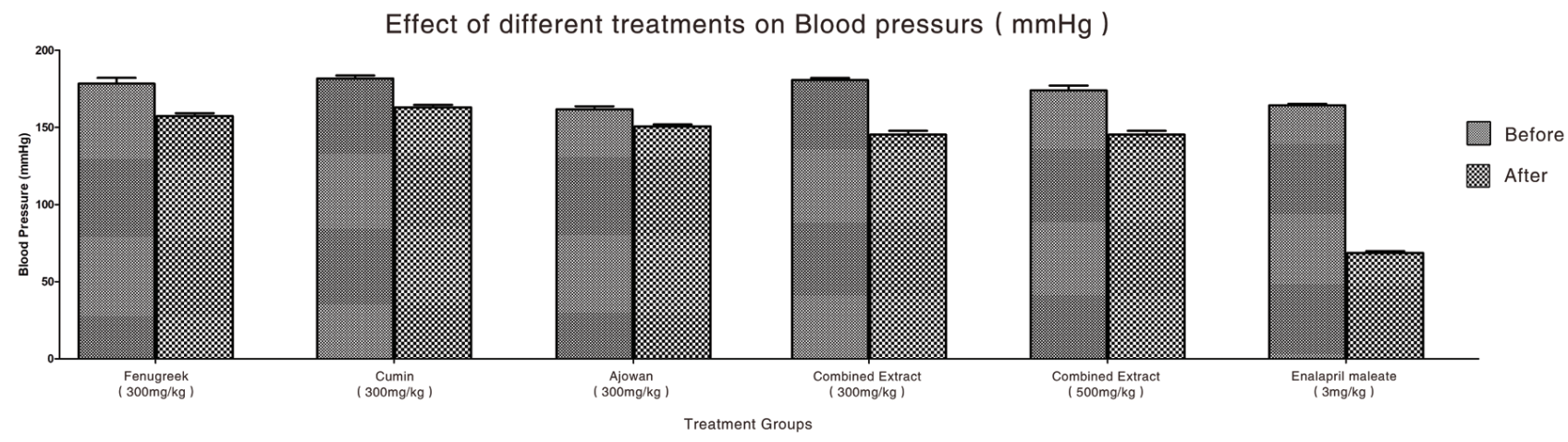

Fig. 1. Effect of different treatments on blood pressures $(\mathrm{mmHg})$.

Table 2. Comparison of the effects of alcoholic extracts on hypocholesterolemic parameters in rats

\begin{tabular}{|c|c|c|c|c|c|c|}
\hline Treatment group & $\begin{array}{l}\text { Total cholesterol, } \\
\text { mg \% }\end{array}$ & $\begin{array}{l}\text { Triglycerides, } \\
\text { mg \% }\end{array}$ & HDL, mg \% & LDL, mg \% & VLDL, mg \% & LDL/HDL, mg \% \\
\hline Vehicle (control) & $157.9 \pm 4.63$ & $88.83 \pm 1.716$ & $12.9 \pm 1.18$ & $127.2 \pm 4.42$ & $17.75 \pm 0.34$ & $10.29 \pm 1.04$ \\
\hline Fenofibrate (10 mg) & $83.52 \pm 2.26^{* *}$ & $47.4 \pm 0.94^{* *}$ & $30.25 \pm 1.72^{* *}$ & $43.79 \pm 3.32 * *$ & $9.38 \pm 0.16^{* *}$ & $1.49 \pm 0.19 * *$ \\
\hline Fenugreek (300 mg) & $107.4 \pm 3.37^{* *}$ & $74.63 \pm 3.51^{* *}$ & $25.93 \pm 1.57^{* *}$ & $66.93 \pm 2.22^{* *}$ & $14.23 \pm 0.81 * *$ & $2.63 \pm 0.14^{* *}$ \\
\hline Cumin (300 mg) & $103.2 \pm 5.61 * *$ & $73.63 \pm 3.62 * *$ & $26.73 \pm 1.25^{* *}$ & $61.93 \pm 6.54 * *$ & $14.7 \pm 0.73 * *$ & $2.38 \pm 0.32 * *$ \\
\hline Ajowan (300 mg) & $140.1 \pm 4.79^{*}$ & $80.15 \pm 1.10^{*}$ & $19.45 \pm 1.03^{*}$ & $108.5 \pm 3.09 *$ & $16.0 \pm 0.19 *$ & $5.47 \pm 0.35^{* *}$ \\
\hline Combined extract (300 mg) & $98.4 \pm 4.47^{* *}$ & $52.85 \pm 1.27^{* *}$ & $22.63 \pm 2.10^{* *}$ & $65.58 \pm 4.22^{* *}$ & $10.52 \pm 0.25^{* *}$ & $3.03 \pm 0.34 * *$ \\
\hline Combined extract (500 mg) & $91.6 \pm 2.49 * *$ & $52.2 \pm 0.73 * *$ & $28.78 \pm 1.31 * *$ & $54.13 \pm 4.50 * *$ & $10.51 \pm 0.14^{* *}$ & $1.93 \pm 0.23^{* *}$ \\
\hline
\end{tabular}

Each value represents mean \pm standard error of the mean for groups of $n=6 .{ }^{*} p<0.05,{ }^{* *} p<0.01$ vs. control group.

significant $(p<0.05)$ decrease in total cholesterol compared to the control with mean value of $157.9 \pm 4.634$ (Table 2, Fig. 2).

Triglycerides' estimations (mg \%)

The groups treated with fenofibrate, fenugreek, cumin, and com- bined extract at a dose of $300 \mathrm{mg} / \mathrm{kg}$ or $500 \mathrm{mg} / \mathrm{kg}$ with mean values of $47.4 \pm 0.942,74.63 \pm 3.509,73.63 \pm 3.616,52.85 \pm 1.271$, and $52.2 \pm 0.7262$ respectively showed significantly $(p<0.01)$ decreased triglycerides compared to the control group with a mean value of $88.83 \pm 1.716$. Similarly, the mean value $47.4 \pm 0.942$ of ajowan showed significant $(p<0.05)$ decrease in HDL-cholesterol compared to control (Table 2, Fig. 3).

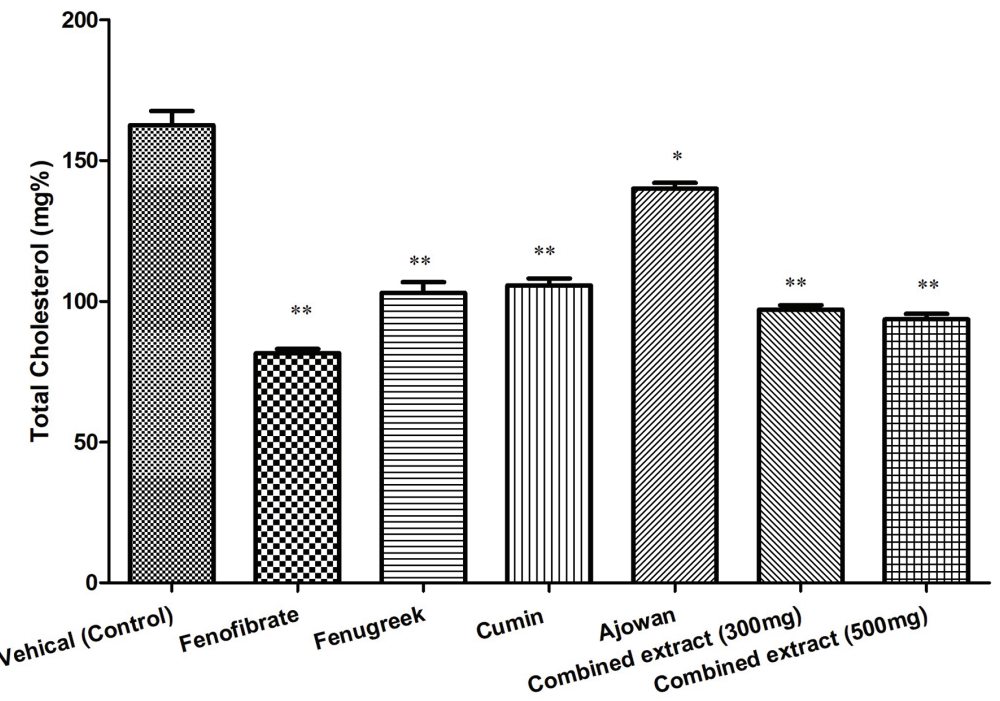

Fig. 2. Total cholesterol (mg\%) in various treated hypercholesterolemic animals. ${ }^{*} P<0.05 ;{ }^{* *} P<0.01$. 


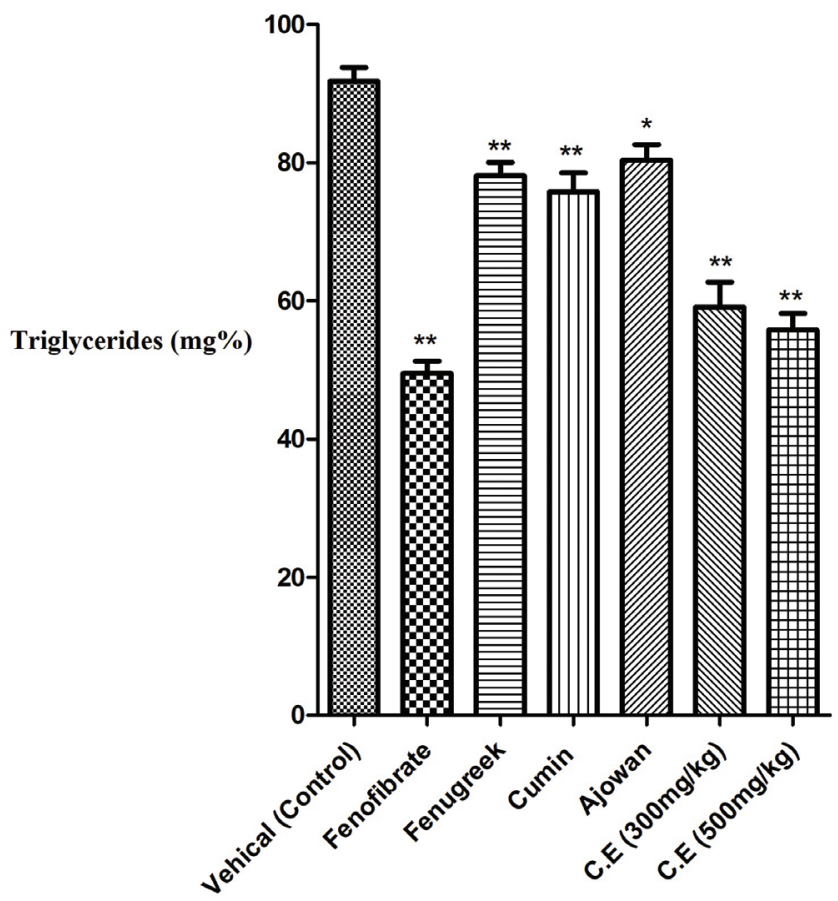

Fig. 3. Triglycerides $(\mathrm{mg} \%)$ in various treated hypercholesterolemic rats. $* P<0.05 ; * * P<0.01$

HDL-cholesterol estimations (mg \%)

The mean values $30.25 \pm 1.715,25.93 \pm 1.574,26.73 \pm 1.245$, $22.63 \pm 2.095$, and $28.78 \pm 1.305$ of fenofibrate, fenugreek, cumin, and combined extract at a dose of $300 \mathrm{mg} / \mathrm{kg}$ - or $500 \mathrm{mg} / \mathrm{kg}$ treated groups respectively showed significant $(p<0.01)$ decrease in HDL-cholesterol compared to the control with mean value of $157.9 \pm 4.634$. Similarly, the mean value $19.45 \pm 1.034$ of ajowan showed significant $(\mathrm{p}<0.05)$ decrease in HDL-cholesterol compared to the control with $157.9 \pm 4.634$ (Table 2, Fig. 4).

\section{LDL-cholesterol estimations (mg \%)}

Fenofibrate, fenugreek, cumin, and combined extract-treated groups with mean values of $43.79 \pm 3.319,66.93 \pm 2.217,61.93$ $\pm 6.535,65.58 \pm 4.224$ and $54.13 \pm 4.495$ respectively showed significant $(p<0.01)$ change in LDL-cholesterol compared to that of the control group with a mean value of $127.2 \pm 4.419$. Similarly, the mean value $108.5 \pm 3.085$ of ajowan showed significant $(p<$ 0.05 ) decrease in LDL-cholesterol compared to control (Table 2, Fig. 5).

\section{VLDL-cholesterol estimations (mg \%)}

The mean values $9.38 \pm 0.1622,14.23 \pm 0.811,14.7 \pm 0.733,10.52$ \pm 0.2496 , and $10.51 \pm 0.1367$ of fenofibrate, fenugreek, cumin, and combined extract at a dose of $300 \mathrm{mg} / \mathrm{kg}$ - or $500 \mathrm{mg} / \mathrm{kg}$-treated groups respectively showed significant $(p<0.01)$ decrease in very VLDL-cholesterol compared to the control with mean value of $17.75 \pm 0.3364$. Similarly, the mean value $16 \pm 0.1915$ of ajowan showed significant $(p<0.05)$ decrease in VLDL-cholesterol compared to the control (Table 2, Fig. 6).

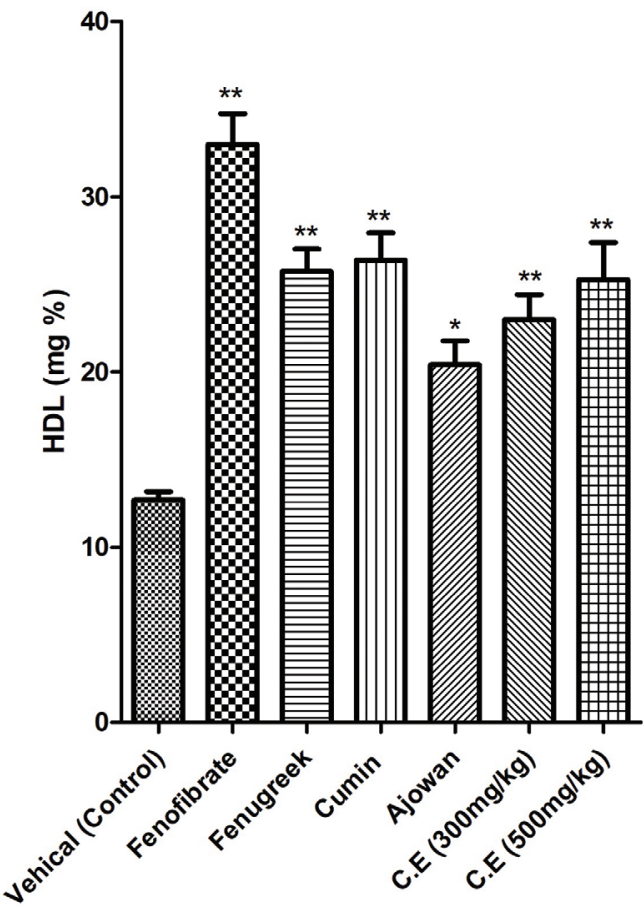

Fig. 4. $\mathrm{HDL}(\mathrm{mg} \%)$ in various treated hypercholesterolemic rats. ${ }^{*} P<0.05$; $* * P<0.01$.

LDL/HDL ratio (mg \%)

Fenofibrate, fenugreek, cumin, ajowan, and combined extracttreated groups with mean values of $1.492 \pm 0.189,2.625 \pm 0.1418$, $2.375 \pm 0.3185,3.033 \pm 0.3355$, and $1.925 \pm 0.2295$ respectively showed significant $(p<0.01)$ change in LDL-cholesterol compared to that of the control group with a mean value of $10.29 \pm$ 1.036 (Table 2, Fig. 7).

\section{Discussion}

In the present study, antihypertensive and hypocholesterolemic activity of fenugreek, cumin and ajowan extracts individually as well as in combination were investigated, both in conscious $1 \mathrm{~K}-1 \mathrm{C}$ Goldblatt hypertensive and hypercholesterolemic rats. The pharmacological data from the present study showed that there was decrease in the blood pressure levels in conscious $1 \mathrm{~K}-1 \mathrm{C}$ Goldblatt hypertensive rats when treated with oral administration for alcoholic extracts of fenugreek, cumin and ajowan, but the significant decrease was found with combined extract of fenugreek, cumin and ajowan at two different doses (i.e. $300 \mathrm{mg} / \mathrm{kg}$ and $500 \mathrm{mg} / \mathrm{kg}$ per os and enalapril maleate at a dose of $3 \mathrm{mg} / \mathrm{kg}$ per os. However, the reduction in blood pressure was not as long lasting as that of enalapril at $3 \mathrm{mg} / \mathrm{kg}$. The reduction was statistically significant with the combined extracts at the two different doses levels (i.e. $300 \mathrm{mg} / \mathrm{kg}$ and $500 \mathrm{mg} / \mathrm{kg}$ ), thus showing good antihypertensive activity in $1 \mathrm{~K}-1 \mathrm{C}$ Goldblatt hypertensive rats.

Several fibric acid derivatives (fibrates) are available, including benzafibrate, ciprofibrate, clofibrate, and fenofibrate. But, these fibrates, in addition to their effects on LDL, can cause increased lithogenicity of bile and increased gallstone incidences, decreased libido, muscle pain, and abdominl discomfort. These effects pro- 
J Explor Res Pharmacol

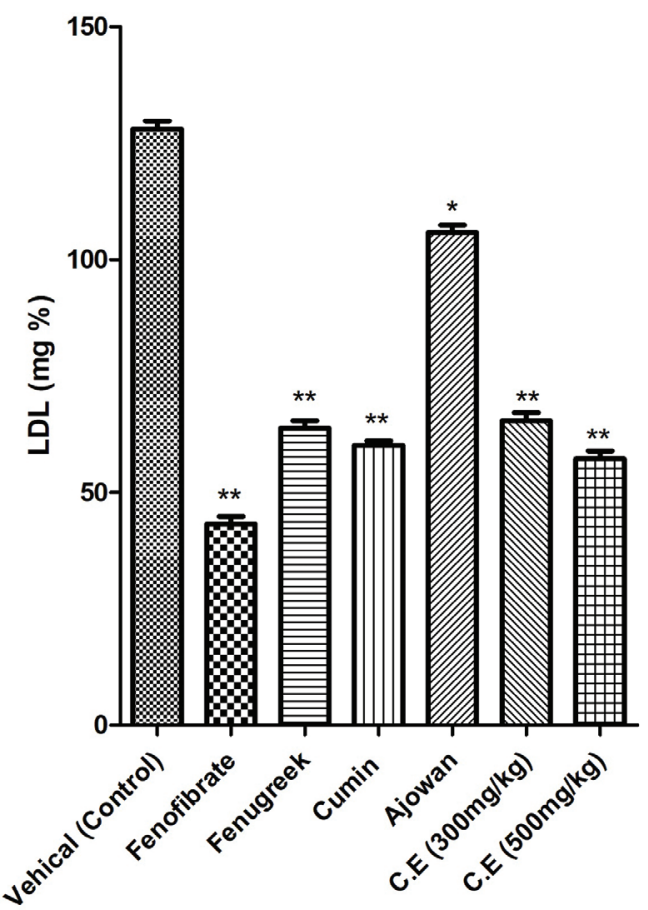

Fig. 5. LDL $(\mathrm{mg} \%)$ in various treated hypercholesterolemic rats. ${ }^{*} P<0.05$; $* * P<0.01$.

mote the need to invent better and safer drugs for long-term use. Keeping this in view, the hypocholesterolemic properties of an ethanol extract from defatted fenugreek (Trigonella foenum graecum) seeds were investigated. Reduction in plasma cholesterol levels

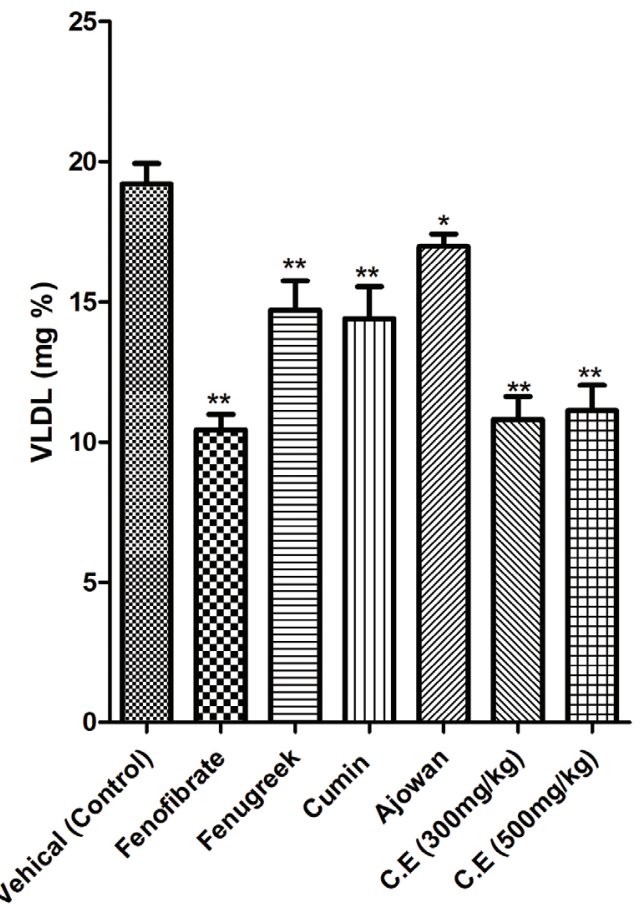

Fig. 6. VLDL $(\mathrm{mg} \%)$ in various treated hypercholesterolemic rats. ${ }^{*} P<$ $0.05 ; * * p<0.01$.
Gurunath S. Effect of herbal formulation on hypertension and atherosclerosis

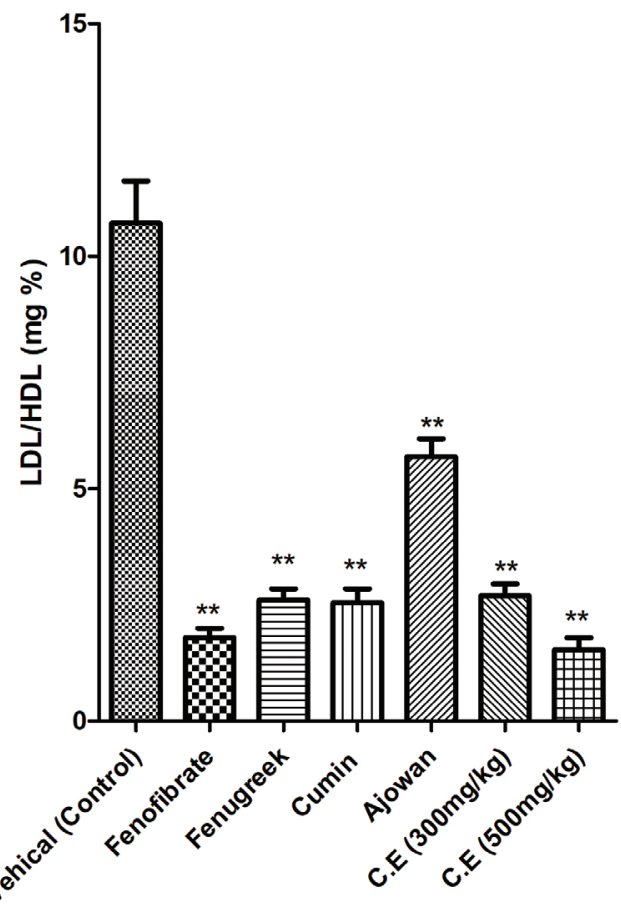

Fig. 7. LDL/HDL (mg\%) in various treated hypercholesterolemic rats. ${ }^{* *} P$ $<0.01$.

ranged from $18-20 \%$ and a tendency for lower concentrations of liver cholesterol was observed. These results indicated that the ethanol extract from fenugreek seeds contained hypocholesterolemic components, which appear to be saponins that interact with bile salts in the digestive tract. Cumin (Cuminum cyminum) has been reported toproduce significant decreases in plasma and tissue cholesterol, phospholipids, free fatty acids, and triglycerides. However, there are no such reports which are known to claim that ajowan (Trachyspermum ammi) possess antihyperlipidemic properties.

The pharmacological data of the present study indicate that alcoholic extracts of fenugreek, cumin, ajowan, and their combination are more potent antihypertensives and are equally effective in lowering total cholesterol, LDL, VLDL, triglycerides, and LDL/ HDL ratio, and work by significantly increasing HDL. The significant antihypertensive and antihypercholesterolemic effect by treatment with the combined extract at two different doses $300 \mathrm{mg} /$ $\mathrm{kg}$ and $500 \mathrm{mg} / \mathrm{kg}$ indicate synergistic interaction between these agents. No such interactions have been reported in the literature. The mechanism, though, appears to be pharmacodynamic in nature. The contribution of pharmacokinetic components cannot be ruled out. Hence, it is very difficult to comment on the mechanism of antihypertensive and antihypercholesterolemic effects of alcoholic extracts. However, considering the rich content of saponins, flavonoids, terpenes and glycosides, and the reported pharmacological effects of the extracts, the observed antihypertensive and antihypercholesterolemic activity in the present study could be attributed to the saponins, flavanoids, terpenes, and glycosides, a theory which is substantiated by earlier reports.

\section{Conclusions}

The combination of alcoholic extracts of fenugreek, cumin and 
ajowan $(300 \mathrm{mg} / \mathrm{kg}$ and $500 \mathrm{mg} / \mathrm{kg}$ ) were found to be more effective for antihypertensive and antihypercholesterolemic activities than the individual extracts. As all the three drugs are widely used in Indian foods and traditional medicine, they are known to be absolutely nontoxic to human beings. Hence, further studies are required to find out the clinical implication of these drugs in combination.

\section{Future research directions/prospective/prediction}

The further studies are being planned to confirm the mechanism of action of these drugs in various animal models and to determine the typical dosage regimens necessary to assess their pharmaceutical avenues.

\section{Funding}

The study did not receive any funding or grants, and was carried out without any financial support.

\section{Conflict of interest}

The author has no conflict of interest related to this publication.

\section{Author contributions}

All works are done by (SG) as a part of patent work.

\section{References}

[1] Robert WM, Thomas PB. Drug therapy for hypercholesterolemia and dyslipidemia. In: Joel GH, Limbird LE. (ed.). Goodman and Gilman's The Pharmacological Basis of Therapeutics, 4th. New York: McGrawHill press. 2001:971-1002.

[2] Nakanishi R, Baskaran L, Gransar H, Budoff MJ, Achenbach S, I-Mallah $\mathrm{M}$, et al. Relationship of hypertension to coronary atherosclerosis and cardiac events in patients with coronary computed tomographic angiography. Hypertension 2017;70(2):293-299. doi:10.1161/HYPERTENSIONAHA.117.09402.

[3] Johnston Cl. New Pharmacologic approaches to the management of hypertension. Am J Hyp 1997;10:299S. doi:10.1016/S08957061(97)00387-7.
[4] Soler EP, Ruiz VC. Epidemiology and risk factors of cerebral ischemia and ischemic heart diseases: similarities and differences. Curr Cardiol Rev 2010;6(3):138-149. doi:10.2174/157340310791658785.

[5] Schmieder RE. End organ damage in hypertension. Dtsch Arztebl Int 2010;107(49):866-873. doi:10.3238/arztebl.2010.0866.

[6] Ya MY, Chien HW, Yueh HT, Chingunin ET, Weng CC. Antioxidative and hypolipidemic effects of barley leaf essence in a rabbit model of atherosclerosis. Jpn J Pharmacol 2002;89:142-148. doi:10.1254/ jjp.89.142.

[7] Al-Shaer MH, Choueiri NE, Suleiman ES. The pivotal role of cholesterol absorption inhibitors in the management of dyslipidemia. Lipids Health Dis 2004;3:22. doi:10.1186/1476-511X-3-22.

[8] Ference BA, Ginsberg HN, Graham I, Ray KK, Packard CJ, Bruckert E, et al. Low-density lipoproteins cause atherosclerotic cardiovascular disease. Evidence from genetic, epidemiologic, and clinical studies. A consensus statement from the European Atherosclerosis Society Consensus Panel. Eur Heart J 2017;38(32):2459-2472. doi:10.1093/ eurheartj/ehx144.

[9] Fallah HH, Sabera MM, Kavoli HM. The effect of captopril, prazosin and methyldopa on atherosclerotic plaque formation in hypercholesterolemic rabbits. Ind J Pharmacol 2002;34:198-201.

[10] Subramanian R, Ramaswamy M, Wasan KM. Role of lipid and lipoprotein metabolizing enzymes in the development of atherosclerosis. Indian J Exp Biol 2003;41(1):14-25.

[11] Badimon L, Padró T, Vilahur G. Atherosclerosis, platelets and thrombosis in acute ischaemic heart disease. Eur Heart J Acute Cardiovasc Care 2012;1(1):60-74. doi:10.1177/2048872612441582.

[12] Nguyen Q, Dominguez J, Nguyen L, Gullapalli N. Hypertension management: an update. Am Health Drug Benefits 2010;3(1):47-56.

[13] Ekor M. The growing use of herbal medicines: issues relating to adverse reactions and challenges in monitoring safety. Front Pharmacol 2014;4:177. doi:10.3389/fphar.2013.00177.

[14] Amos S, Akah PA, Binda L, Enwerem NM, Ogundaini A, Wambebe $C$, et al. Hypotensive activity of the ethanol extract of Pevette Crassipes leaves. Biol Pharm Bull 2003;26(12):1674-1680. doi:10.1248/ bpb.26.1674.

[15] Cragg GM, Newman DJ. Natural products: a continuing source of novel drug leads. Biochim Biophys Acta 2013;1830(6):3670-3695. doi:10.1016/j.bbagen.2013.02.008.

[16] Yadav UC, Baquer NZ. Pharmacological effects of Trigonella foenumgraecum L. in health and disease. Pharm Biol 2014;52(2):243-254. d oi:10.3109/13880209.2013.826247.

[17] Puri D, Prabhu KM, Murthy PS. Mechanism of action of a hypoglycemic principle isolated from fenugreek seeds. Ind J Physio Pharmacol 2002;46(4):457-462.

[18] Nadkarni AK. Indian Materia Medica, Vol. I. Mumbai: Popular Prakasan. 1998:1028.

[19] Aslam M. Aspects of Asian medicine and its practice in the West. Trease and Evans' pharmacognosy. UK: Saunders Company Itd. 1997:447-649.

[20] Bairwa R, Sodha RS, Rajawat BS. Trachyspermum ammi. Pharmacogn Rev 2012;6(11):56-60. doi:10.4103/0973-7847.95871. 